Nunt. Antiquus, Belo Horizonte, v. 16, n. 1, p. 77-99, 2020

\title{
Autoria, cânone retórico e polifonia nas Declamações maiores de Pseudo-Quintiliano
}

\section{Authorship, Rhetoric Canon and Polyphony in Ps-Quintilian's Major Declamations}

\author{
Beatriz Rezende Lara Pinton \\ Universidade Federal de Juiz de Fora, Juiz de Fora, Minas Gerais / Brasil \\ beatriz.rlp5@gmail.com \\ https://orcid.org/0000-0002-9004-1759

\section{Charlene Martins Miotti} \\ Universidade Federal de Juiz de Fora, Juiz de Fora, Minas Gerais / Brasil \\ charlene.miotti@letras.ufjf.br \\ https://orcid.org/0000-0002-4288-0398
}

\begin{abstract}
Resumo: O objetivo deste artigo é analisar o contexto de produção das Declamações maiores atribuídas a Quintiliano, escritas entre os séculos I e IV EC. Uma vez que o gênero declamatório surgiu no mundo greco-romano como um exercício escolar, é possível conjugar os preceitos teóricos da educação retórica no Império Romano com a prática das declamações, identificando em que medida os cânones literários recomendados no livro $\mathrm{X}$ da Institutio oratoria influenciam na construção das personagens das Declamações maiores 14 e 15, objetos deste estudo. Também se investiga quais sujeitos tinham acesso à educação em Roma, os possíveis praticantes e autores das declamações e como tais textos manifestam, por meio de personagens, diferentes personae e vozes, oriundas de diversas camadas sociais. Este artigo se propõe a demonstrar que a leitura da obra não pode se guiar apenas pela função-autor, distanciando a produção dos sujeitos históricos que supostamente a compuseram. Ao tratar de temas como tensões entre homens ricos e pobres, estupro, abuso de poder e deserdação, o gênero declamatório pode - à primeira vista - ser interpretado como uma ferramenta contundente de discussão social e denúncia. No entanto, considerando o seu contexto de produção e os prováveis declamadores, propõe-se que as declamações ao mesmo tempo contribuem e rompem com as narrativas de poder, traçando algumas possibilidades de negociar identidades e alianças por meio das personagens do cânone estabelecido.
\end{abstract}


Palavras-chave: declamações; Pseudo-Quintiliano; cânone; personae; polifonia.

Abstract: The purpose of this article is to analyze the context of production of the Major Declamations ascribed to Quintilian and written between I and IV CE. Since the declamatory genre emerged in the Greco-Roman world as a type of school exercise, it is possible to conjugate the theoretical precepts of the rhetorical education in the Roman Empire with the declamatory practice, identifying in which measure the literary canons recommended in the 10th book of the Institutio oratoria had influence in the construction of the characters from the Major Declamations 14 and 15, objects of this study. This paper also investigates which subjects had access to education in Rome, the possible practitioners and authors of the declamations, and how these texts manifest, through their characters, different personae and voices coming from varied social backgrounds. In addition, this article seeks to demonstrate that the reading of this work cannot be guided just by the author's function, detaching the production from the historical subjects who composed it. Because it deals with themes such as tensions between rich and poor, rape, abuse of power and disinheritance, the declamatory genre may be interpreted -at first sight-as a strong tool for social discussion and denunciation. However, considering the context of production and the likely reciters, thi study proposes that the declamations contribute and break with the narratives of power at the same time, drawing some possibilities to negotiate identities and allegiances through characters of an established canon.

Keywords: declamations; Pseudo-Quintilian; Canon; Personae; Polyphony.

\section{Diálogos entre correntes literárias contemporâneas e a autoria na Antiguidade}

A partir da corrente do New Criticism, a teoria literária sofreu grandes mudanças. O movimento teve início nos Estados Unidos, durante a década de 20 e contou com os escritores T. S. Eliot e William Empson como dois dos seus principais precursores. Os integrantes da nova corrente rejeitavam as interpretações que se apoiavam em elementos como a biografia ou a suposta intenção do autor. Assim como os formalistas russos, denunciavam as antigas vertentes positivistas, voltando-se para a primazia do texto. Buscando análises literárias menos subjetivas, que se aproximassem mais dos preceitos científicos, "[...] os formalistas russos e os New Critics americanos eliminaram o autor para assegurar a independência dos estudos literários em relação à história e à psicologia" (COMPAGNON, 2014, p. 48). Ao estabelecer a 
separação entre texto e autor, os New Critics se afastam do problema da intencionalidade ou, assim como referido por eles, intentional fallacy, a falácia da intenção, ou seja, o entendimento de que deve-se procurar no texto o que o autor quis dizer ou ainda de que é possível identificar ou correlacionar diretamente as situações e sentimentos presentes na obra com a vida do autor empírico.

Rejeitando também a análise biografista das obras e aderindo às ideias do New Criticism, Foucault (1997 [1969]) desenvolveu a noção da função-autor, na qual se percebe o autor como uma função discursiva do texto, que não está necessariamente correlacionado com o sujeito histórico. Ou seja, a interpretação de um texto pode dispensar elementos externos, dados da vida de quem o escreveu, transferindo o foco da interpretação para o leitor, que toma como base as informações do próprio texto, os elementos concretos e analisáveis da obra, bem como o contexto histórico de produção. O leitor, dessa forma, passa a ser o centro da investigação literária, porque é nele que se reúne o sentido, a ele cabe a interpretação. Barthes (1988 [1968], p. 70) afirma que "o nascimento do leitor deve pagar-se com a morte do Autor", apontando a necessidade de deixar para trás a análise literária biografista e voltar a atenção para o receptor do discurso, o que posteriormente também abre caminhos para as teorias e estudos da recepção.

Alguns teóricos contemporâneos, como Antoine Compagnon (2014), revisitaram as teses dos New Critics, assim como dos formalistas russos, levantando questionamentos que modalizam a separação entre autor e obra, abrindo espaço de reflexão sobre a questão da intenção:

Mas ao afirmar que o autor é indiferente no que se refere à significação do texto, a teoria não teria levado longe demais a lógica, e sacrificado a razão pelo prazer de uma bela antítese? E, sobretudo, não teria ela se enganado de alvo? Na realidade, interpretar um texto não é sempre fazer conjeturas sobre uma intenção humana em ato? (COMPAGNON, 2014, p. 49).

Tomamos as correntes literárias sobre autoria como referência para a elaboração do artigo, porque no que concerne à coletânea das 
Declamações maiores, objeto da nossa pesquisa, não é possível rastrearmos o sujeito histórico que as compôs. Sussman (1987, p. viii) afirma que provavelmente as Declamações maiores foram obra de vários oradores, compiladas posteriormente em um único livro. As suas identidades são anônimas, restando dúvidas até mesmo sobre o envolvimento do próprio Quintiliano na composição das declamações. O mais provável é que os discursos tenham sido escritos e proferidos por alunos ou seguidores da escola de retórica de Quintiliano (CORBEILL, 2015, p. 11). Assim, mesmo se pretendêssemos fazer uma interpretação biografista, faltariam os dados mais elementares, como a própria identidade dos autores. Além disso, devemos considerar que a questão da autoria funcionava no mundo clássico de forma distinta da modernidade.

Os New Critics, no entanto, assumiam que a pesquisa sobre o contexto histórico colaborava para a compreensão do gênero literário, das consequências político-sociais, assim como para a representação literária de fenômenos históricos relevantes em cada época e sociedade. Para isso, consideramos que informações tais como o gênero, a posição social e os espaços aos quais o autor pertence podem servir como sinalizadores da sua visão de mundo, transposta em certo grau para a obra. Os declamadores, enquanto sujeitos históricos, eram homens da elite romana, educados desde a infância na arte da retórica, que através dos seus discursos poderiam influenciar social e politicamente os pares à sua volta, inclusive abordando temáticas morais (LANGLANDS, 2006, p. 250). Assim, quando nos propomos a voltar o olhar para o contexto de produção das declamações, é imprescindível que tracemos o perfil social e histórico daqueles que se dedicaram à prática da retórica.

Também a corrente teórica do New Historicism aponta para a relação entre a literatura e a sociedade, do ponto de vista histórico e envolvendo demais ciências como etnografia, antropologia e história da arte. Harold Veeser (1989, p. xi) estabelece alguns dos princípios do movimento do New Historicism, para os quais todos os teóricos convergem, apesar das análises e vertentes distintas: 
Um principiante no New Historicism pode sentir-se confiante de que, apesar de toda sua heterogeneidade, pressupostos-chave continuamente reaparecem, vinculando seus adeptos declarados e, até mesmo, alguns de seus críticos. Esses pressupostos são os seguintes: 1. Que todo ato expressivo está inserido em uma rede de práticas materiais; 2. Que cada ato de desmascaramento, crítica e oposição usa as ferramentas que condena e corre o risco de cair na prática que expõe; 3. Que os "textos" literários e não-literários circulam inseparavelmente; 4. Que nenhum discurso, imaginativo ou arquivístico, dá acesso a verdades imutáveis nem expressa a inalterável natureza humana; 5. Finalmente, como emerge poderosamente nesse volume, que um método crítico e uma linguagem adequada para descreverem a cultura sob o capitalismo participam da economia que descrevem. Os New Historicists combatem o formalismo vazio ao colocar as considerações históricas no centro da análise literária. ${ }^{1}$ (VEESER, 1989, p. xi, tradução nossa).

O primeiro princípio elencado por Veeser (1989) afirma que atos expressivos, ou seja, a própria ação de escrever um discurso, um texto, de produzir literatura, estão vinculados a uma rede de práticas materiais. Logo, pesquisar a história da retórica sob o Império e o gênero declamatório são pontos fundamentais para compreender em quais

\footnotetext{
1 "A newcomer to New Historicism might feel reassured that, for all its heterogeneity, key assumptions continually reappear and bind together the avowed practitioners and even some of their critics; these assumptions are as follows: 1. that every expressive act is embedded in a network of material practices; 2 . That every act of unmasking, critique, and opposition uses the tools it condemns and risks falling prey to the practice it exposes; 3 . That literary and non-literary 'texts' circulate inseparably; 4 . That no discourse, imaginative or archival, gives access to unchanging truths nor expresses inalterable human nature; 5. Finally, as emerges powerfully in this volume, that a critical method and a language adequate to describe culture under capitalism participate in the economy they describe. The New Historicists combat empty formalism by pulling historical considerations to the center stage of literary analysis."
} 
práticas materiais o nosso corpus está inserido. O terceiro e o quarto princípio revelam que textos literários podem servir como fonte histórica, se tomarmos os documentos chamados "oficiais" também como resultado de discursos e narrativas. Embora seja necessário cautela ao analisar os aspectos históricos de uma obra literária, também cabe ressaltar que, no mundo antigo, literatura, ficção e história se confundiam, todas compondo partes de um mesmo relato.

\section{Questões de autoria na Antiguidade: auctor, poeta e rhetor}

$\mathrm{Na}$ Antiguidade, a questão da autoria certamente não seguia os mesmos preceitos que podemos hoje identificar na teoria literária, motivo pelo qual também não convém aplicar diretamente as teorias contemporâneas aos textos antigos. O teórico estadunidense Diskin Clay (1998) se propõe a investigar como os antigos percebiam a figura do autor e qual era o nível de consciência acerca da diferença entre o autor empírico e a persona literária. De acordo com Clay (1998, p. 15), quem primeiro cunhou o conceito de persona para os Estudos Clássicos foi William S. Anderson (1964), em um artigo sobre Juvenal, a partir da teoria de Booth (1983 [1961]) sobre a retórica da ficção. O autor antigo - em especial o autor de prosa - se apresentaria por meio de uma personagem projetada em sua obra, não para propósitos de confissão ou autorrevelação, mas com a função retórica de persuadir.

Clay (1998, p. 16) chama a atenção principalmente para o processo que levou os antigos a reconhecerem a diferença entre auctor e actor, sinalizando que nem sempre houve clareza nesta distinção. A poesia era difundida, sobretudo, no contexto oral, cantada e recitada, fazendo com que a figura do autor estivesse pessoalmente associada à do declamador ou narrador. Logo, tornava-se mais difícil enxergar a diferença entre a figura que produzia e aquela que performava diante do público. À exceção das personagens que podiam ser distinguidas pelas diferentes máscaras e vozes, o narrador não podia personificar aquilo que já era. A noção de autor era palpável e concreta, difícil de ser dissociada do indivíduo que se apresentava em público. 
Embora Clay (1998, p. 9) não se proponha a pensar na prática ou nas estratégias retóricas utilizadas pelos poetas antigos, é procedente assumir que tais práticas existiam. Ao criar uma máscara, o autor também estava preocupado com a sua capacidade de persuadir. Nos gêneros retóricos, a consciência da máscara parece ser mais marcada, já que a sua utilização e domínio adequados são fundamentais para a prática oratória.

Os críticos retóricos estavam bem conscientes do quão importante era a projeção de uma personagem para o sucesso de um discurso e a teoria da êthopoiía tem uma longa corrente que é paralela a, mas não se intersecciona com as linhas de questionamento que nós temos seguido. (CLAY, 1998, p. 39, tradução nossa).

Assim, o estudioso sugere que a teoria da persona ocorre de maneira diferente na poesia e na retórica. Enquanto os poetas enfrentam grande dificuldade em se dissociarem da imagem que criam nos poemas, entre os oradores parece haver um consenso no que diz respeito ao aspecto construído do êthos do orador. Discordamos, contudo, da premissa de que na retórica é possível distinguir com tanta consciência o orador empírico do seu êthos. Ainda que seja recomendado moldar a sua máscara às necessidades de cada caso, o orador deve se esforçar para ser um homem bom (uir bonus). Embora o termo suscite discussões quanto ao seu teor, porque também pode apontar para a posição social do indivíduo, é um indicativo de que o orador deve cultivar virtudes que condigam com as que exalta em seus discursos. A reputação precede o discurso do orador, já que ao se aproximar do ideal de figura pública e política, mais credibilidade também é conferida às suas palavras (MIOTTI, 2010, p. 45). A tese do orador como vir bonus dicendi peritus é catoniana, mas Quintiliano também irá endossá-la na Institutio Oratoria.

\footnotetext{
2 "Rhetorical critics were well aware of how important the projection of character was to the success of a speech and the theory of èthopoiía has long career that is parallel to, but does not intersect, the lines we have been following."
} 
Ora, nós estamos formando aquele orador perfeito, que não pode ser senão um homem de bem, e por isso não lhe cobramos apenas uma excelente habilidade no discursar, mas todas as virtudes do espírito. Pois eu não admitiria que o modelo de uma vida reta e honesta, como pensaram alguns, deva ser atribuído aos filósofos, quando o verdadeiro cidadão, talhado para a administração das coisas públicas e privadas, capaz de comandar as cidades com seus conselhos, firmá-las com suas leis, corrigi-las com seus julgamentos, não pode ser outro, na verdade, senão o orador. ${ }^{3}$ (Inst., 1.pr.9-10, tradução de Marcos Pereira, 2001, p. 150).

De acordo com tal preceito, a retórica não poderia ser a arte de persuadir a qualquer custo: era necessário ter uma causa justa e ser moralmente nobre. Além de educados para se tornarem oradores, os jovens da elite também eram formados para a vida pública e para exercer a cidadania romana. Apesar das mudanças políticas advindas do Principado, Quintiliano dá a entender que o orador ainda é uma figura influente na sociedade, detentor de vasto conhecimento e de senso de justiça.

Segundo Falcón (2015, p. 20), "o uir bonus, isto é, o componente moral da retórica, não pareceria assim estar descolado do aspecto técnico, justamente porque já não falamos de uma ars com fins puramente utilitários, mas de um símbolo cultural e, portanto, moral'. Logo, o fato de a retórica ser um dos objetos mais importantes do currículo escolar romano aponta para a consolidação dos valores morais por meio da educação. A formação do cidadão romano letrado deveria passar pelas escolas de retórica e, por consequência, aprendia-se não somente as habilidades técnicas do discurso, mas também eram propagadas as noções culturais e morais vigentes dentro daquela sociedade.

\footnotetext{
3 "Oratorem autem instituimus illum perfectum, qui esse nisi uir bonus non potest, ideoque non dicendi modo eximiam in eo facultatem sed omnis animi uirtutes exigimus. Neque enim hoc concesserim, rationem rectae honestaeque uitae, ut quidam putauerunt, ad philosophos relegandam, cum uir ille uere ciuilis et publicarum priuatarumque rerum administrationi accommodatus, qui regere consiliis urbes, fundare legibus, emendare iudiciis possit, non alius sit profecto quam orator."
} 
Nossa própria leitura desses aspectos de mudança não foi beneficiada pela erudição moderna, que, às vezes, tentou examinar declarações teóricas sem levar em conta a função cultural da retórica em uma dada sociedade ou meio intelectual, ou tentou considerar a retórica como se fosse apenas um ato linguístico ou de função pública: pois a retórica é a prática e a teoria ideal, e também produz textos literários. (SCHOECK, 2017, p. 3).

Portanto, como Schoeck (2017) sintetiza, não é possível pensar apenas no aspecto teórico ou prático da arte retórica, porque ambos estão correlacionados e, se considerarmos o seu contexto escolar e sua função civil, é também necessário que o discurso esteja atrelado à prática. Capaz de conjugar ambos os aspectos, a declamação se consagrou como a expressão mais popular da retórica sob o Império (PERNOT, 2005, p. 151). As declamações surgem como exercício retórico escolar, o último estágio de formação dos jovens oradores, "em que acontecia a transição dos estudos teóricos e das técnicas, praticadas junto ao grammaticus e ao rhetor, para um conhecimento funcional" (REZENDE, 2009, p. 136). Além de compor um discurso, utilizando-se de todo o conhecimento acumulado durante a formação, os jovens oradores também o proferiam em público, fosse em sessões privadas ou públicas, que aconteciam nas próprias escolas. Logo, o formato também ganhou prestígio entre os declamadores célebres, que exibiam seus talentos em eventos públicos, por entretenimento (BONNER, 1949, p. 81).

\section{Construções do êthos nas Declamações maiores 14 e 15}

As Declamações maiores apresentam um subgênero de declamações, as controvérsias, que se voltavam para a elaboração de discursos do gênero judicial: o professor escolhia um tema controverso a ser debatido pelos declamadores, com base em alguma lei, que poderia ser real ou parcialmente modificada (GONZÁLEZ, 2015, p. 945). A partir desta escolha, os alunos deveriam compor um discurso em defesa de uma das partes. Caberia aos declamadores inserirem os detalhes do 
caso, tornando-o mais verossímil, assim como atribuir personalidade e emoções adequadas às personagens envolvidas.

Em algumas declamações, as próprias personagens litigantes dão o testemunho e, em outras, revela-se mais adequado que o orador discurse em primeira pessoa, situação que demanda que o aluno construa o êthos apropriado para a defesa do caso. O professor era o encarregado de apontar aos alunos qual seria a melhor abordagem, dependendo do tema a ser tratado (CORBEILL, 2015, p. 16). Mas se levarmos em consideração que as Declamações maiores foram atribuídas a Quintiliano por se relacionarem de alguma forma com os seus preceitos teóricos, chegamos à conclusão de que os advogados representados em primeira pessoa nas declamações deveriam ser construídos de acordo com as necessidades retóricas, mas em contrapartida também refletiam o modelo de uir bonus que os jovens almejavam se tornar. Neste contexto, é possível discernir completamente o orador empírico da persona retórica?

Nas Declamações maiores 14 e 15, analisamos o caso de uma meretriz que oferece uma poção de ódio ao seu cliente, um jovem pobre que sofria dos males excessivos do amor. Na coletânea das Declamações, esse é um dos poucos casos que apresentam acusação e defesa. ${ }^{4} \mathrm{O}$ jovem acusa a meretriz de envenenamento, alegando que a poção o subjugara a um estado conflituoso de espírito em que amor e ódio se digladiavam, sem que nenhum dos dois sentimentos intensos fosse apaziguado, deixando-o numa sensação de ira e tormento constantes. A acusação é feita pela persona do adolescente, que narra seus próprios infortúnios.

A defesa, por outro lado, é atribuída a um orador: em primeiro lugar, porque não era comum que as mulheres pudessem falar nos tribunais, especialmente as de classe inferior. As prostitutas, sobretudo, eram consideradas infames desde o final da República e começo do Principado. Esse status jurídico definia que elas não eram autorizadas a fazer acusações, nem a depor a favor de outras pessoas. Além disso, eram frequentemente espancadas e violentadas, com relativa impunidade para os seus agressores (EDWARDS, 1997, p. 66). Considerando, portanto,

\footnotetext{
${ }^{4}$ Além desse, temos apenas o caso do filho suspeito de incesto com a sua mãe, apresentado também no formato de acusação e defesa, nas Declamações maiores 18 e 19.
} 
a reputação atribuída às meretrizes, a mediação de um orador serviria para conferir maior credibilidade à defesa. Ao mesmo tempo em que o orador faz elogios ao caráter generoso e caridoso da ré, a defesa também faz uso de pronomes e verbos na primeira pessoa do plural, como uma estratégia de persuasão, na qual o advogado reafirma a sua boa reputação e constrói um êthos positivo para a meretriz:

Portanto, que o acusador não vos engane nesta lamentação inicial sobre seu destino, como se tivesse sido arruinado pela caridade da meretriz. Estai seguros da nossa inocência: tal como a conheceu, assim se apaixonou. Nada tinha a perder em tão imoderado ardor, a não ser a cabeça. ${ }^{5}$ (Decl. maiores, 15.2, tradução nossa, grifo nosso).

Ao longo da declamação, a defesa não nega que a prostituta tenha administrado uma poção ao jovem, mas argumenta que aquele era o último remédio possível para livrá-lo da obsessão. A linha de argumentação se baseia na construção da figura da acusada como meretrix bona, que apesar da sua ocupação, é virtuosa, clemente e coloca a predisposição em ajudar acima dos seus próprios interesses.

Temo que se eu começar a exaltar o comportamento da inocentíssima moça, $<$ se $>$ trouxer à tona a sua integridade, o pobre voltará a amá-la novamente. Seja porque, juízes, a perversidade das crenças humanas chama uma mulher bonita e não casada de prostituta, seja porque algum amante impôs este nome à coitada - à qual o destino não concedeu, junto com as belezas do corpo, meios necessários à castidade de um casamento rigoroso -, no entanto ela batalhou, dentro da sua situação crítica, para conservar a honra. ${ }^{6}$ (Decl. maiores 15.2, tradução nossa).

\footnotetext{
5 "igitur accusator hac prima fortunae suae conploratione decipiat, tamquam meretricis caritate consumptus sit. securi estote pro innocentia nostra, talis incidit, talis adamavit, nec habuit, quod perderet in tam inmodico ardore nisi mentem."

6 "Timeo, ne, si coepero simplicissimae puellae laudare mores, referre probitatem, amare rursus pauper incipiat. sive enim, iudices, malignitas est persuasionis humanae
} 
Neste trecho da defesa, o orador faz a representação da meretriz como bona, através da recorrência de expressões como simplicissimae, laudare mores e custodire probitatem. O uso destes termos, na verdade, faz com que ela se aproxime muito mais de um ideal de matrona romana, o que de acordo com o advogado, só não teria sido possível porque a moça não dispunha dos meios (unde sufficeret), ou seja, de um dote para se casar.

\section{Diálogos com o cânone literário}

Ao utilizarem as personagens-tipo da literatura greco-romana, como o adolescente que sofre por amor e a meretriz bondosa, as declamações ressaltam o seu caráter literário, fundindo-se às influências do cânone que estavam na base da formação escolar dos jovens oradores. Alguns autores argumentam que o gênero declamatório também abriu espaço para a criação imaginativa e a experiência autoral (CONNOLY, 2015, p. 201; SCHWARTZ, 2004, p. 14, 78). O próprio Quintiliano atesta a função de entretenimento da declamação, defendendo que a sua natureza não era exclusivamente jurídica - logo, eram permitidas as liberdades poéticas dos jovens aprendizes, desde que o mestre se certificasse de que os temas não fossem muito fantasiosos e que o exercício cumprisse a sua função final de preparação para os casos reais;

Se a declamação, contudo, é feita para a exibição, é claro que devemos inclinar-nos em alguma medida ao prazer dos ouvintes. [...] A declamação, portanto, como é a imagem da eloquência judicial e deliberativa, deve assemelhar-se à vida real; mas como possui um elemento epidíctico, deve possuir algum grau de elegância. É o que fazem os atores cômicos: quando apresentam seus discursos, não imitam exatamente a fala cotidiana, porque não haveria aí arte, nem por outro lado afastam-se muito

formam vacantem vocare meretricem, seu miserae nomen istud inposuit aliquis amator, cui cum corporis bonis fortuna non dederat, unde severi matrimonii castitati sufficeret, laboravit necessitatium suarum custodire probitatem." 
da natureza, um defeito que destruiria a imitação; em vez disso ornamentam, com certo decoro teatral, o modo costumeiro de se falar. (Inst. 2.10.10-13, tradução de Rafael Falcón).

Quintiliano se refere ao aspecto oral das declamações, que eram recitadas nas sessões abertas ao público, diante de uma audiência de pais, professores e outros oradores. Ao aproximarmos as declamações do teatro, temos uma pista sobre a inspiração das personagens declamatórias, que muitas vezes são oriundas da comédia, como o escravo, a virgem, a matrona, o homem pobre e o homem rico, a meretriz, o soldado. $\mathrm{O}$ amante adolescente está presente tanto nas peças cômicas, gastando indiscriminadamente o dinheiro do pai, como na elegia, rivalizando com os outros pretendentes da amada e passando a noite na soleira, diante da porta fechada (LANGLANDS, 2006, p. 254).

Schoeck (2017, p. 3), ao tratar da influência entre os cânones retóricos de diversas épocas, fazendo uma genealogia da Antiguidade até a Europa do Renascimento, assim define a intertextualidade, de acordo com Greene (1982, p. 16):

A intertextualidade descreve - para usar a encantadora expressão de Thomas Greene - o itinerário ou a genealogia de uma imagem complexa, de um conceito rebuscado ou de um texto, e talvez possa ser ela própria definida como "a presença estrutural" dentro de uma obra de "elementos oriundos de obras anteriores"; como Greene, com razão, observa: "já que a ideia de um texto literário que não carrega nada de seus predecessores é inconcebível, a intertextualidade é uma constante literária universal". (SCHOECK, 2017, p. 3).

Assim, quando pensamos na inserção de personagens de origem literária nas declamações, estamos nos referindo simultaneamente à intertextualidade com poetas e dramaturgos antigos, bem como à validação do cânone retórico, uma vez que é possível identificar que as obras recomendadas por Quintiliano continuaram a ser lidas pelos 
jovens oradores, que se valiam de modelos literários para elaborar sua argumentação retórica e suas personagens. No livro 10 da Institutio Oratoria, Quintiliano oferece um catálogo de obras de autores gregos e latinos importantes para a formação do orador. Este catálogo contribuiu para a consolidação do cânone literário, apresentando uma listagem que inclui vários gêneros, como a épica, a elegia, a sátira, a comédia, a tragédia, entre outros. A poesia, num geral, deve ser lida porque auxilia na elegância do discurso e na caracterização das personagens.

Verdadeiramente dos poetas se busca o sopro, que é vida nas ideias; a sublimidade, que se eleva nas palavras; todos os movimentos que se agitam nos afetos; a caracterização que existe nas personagens; principalmente porque a mente, desgastada no agir diário do fórum, como que se restaura, no seu melhor, por meio desta liberdade de tudo. (Inst. 10, 1, 27, tradução de Antonio Rezende).

Fica implícito que a poesia não serve apenas para educação formal, mas é também fonte de deleite. Através da leitura do cânone, também é possível aprender sobre decoro, elegância no estilo e eloquência. Os afetos são um item importante, porque o orador deve se empenhar em dominá-los e utilizá-los da maneira adequada. Ao especificar as características dos gêneros e autores, Quintiliano ainda faz comentários sobre a respectiva inspiração que cada um poderia proporcionar para os jovens oradores. Na comédia, sobressai a diversidade das personagenstipo e a sua representação.

De minha parte, no entanto, penso que ele [Menandro] $]^{7}$ há de levar algo mais de contribuição aos declamadores, já que a estes é necessário, segundo a natureza das controvérsias, se comportarem como os mais diferentes personagens, ou seja, como pais, filhos, <solteirões $>$, maridos, soldados, camponeses,

\footnotetext{
${ }^{7}$ Menandro (342-291 a.C.), comediógrafo grego, representante da Comédia Nova, que serviu de inspiração para dramaturgos latinos como Plauto e Terêncio.
} 
ricos, pobres, mal-humorados, suplicantes, amáveis, ríspidos. Em todos estes retratos a perfeita imagem é admiravelmente guardada por esse poeta. (Inst. 10.1.72, tradução de Antonio Rezende).

Além de Menandro, Quintiliano também recomenda a leitura de Terêncio (Inst.10. 1. 99), ainda que considere as comédias gregas melhores que as latinas. No caso da poção de ódio, o modelo da meretrix bona pode ser identificado como uma característica das peças terencianas (GILULA, 1980). Ainda que as narrativas sejam diferentes, a meretriz da nossa declamação é construída a partir do mesmo êthos das prostitutas Taís, de Hecyra e Báquides, de Eunuchus, que procuram se afastar do estereótipo vil, provando boas intenções em relação ao amante adolescente. Ao invés de exigirem presentes e desperdiçarem o dinheiro do jovem, as boas prostitutas são altruístas e provam as suas virtudes ao demonstrarem lealdade ao amante e respeito à estrutura da família romana e às hierarquias sociais de poder (STRONG, 2016, p. 44).

\section{A polifonia no gênero declamatório}

É possível identificar nas declamações a presença de inúmeras vozes, distintas entre si e, em geral, contrárias, porque se opõem umas às outras, como é esperado nas controvérsias. Encontramos também uma ampla variedade social e de gênero, representada por virgens, prostitutas, esposas, escravas e homens de diferentes estratos. Essas personagens, no entanto, expressam um ponto de vista condizente com as suas posições sociais? O esforço do declamador, sem dúvidas, é fazer com que essas representações sejam verossímeis, mas de acordo com qual referente? Ou seja, as personagens buscam ser verossímeis em relação aos sujeitos históricos, ao homem pobre, à prostituta romana ou às suas versões literárias, já previamente construídas pelo gênero cômico?

Para refletir sobre tais questões, partimos da noção de dialogismo de Bakhtin, na qual a literatura, o discurso, o texto, tudo aquilo que pode se remeter a um autor é um artefato de natureza social. Logo, os discursos estão em constante movimento dialógico, seja de convergência ou divergência, adesão ou recusa, porque neles sempre se produz o debate 
do sujeito e do Outro. Assim, todo enunciado possui dimensão dupla, porque carrega duas posições, dois pontos de vista (FIORIN, 2005, p. 170).

Nas declamações, o movimento dialógico é distinguível porque sempre há o outro, a outra parte litigante, por mais que não existam os dois textos materiais. A maior parte das declamações conta com apenas um dos lados do discurso, sendo este o formato mais usual encontrado tanto na obra das Declamações maiores quanto nas menores. Portanto, não são necessários ambos os textos para identificar a posição contrária. Uma das estratégias retóricas é justamente contra a argumentação, que busca refutar o adversário antes que ele tenha a oportunidade de expor seus argumentos.

Em que medida, porém, podemos dizer que as declamações são polifônicas? E por polifônico, entendemos o termo cunhado por Bakhtin, um texto no qual

cada personagem funciona como um ser autônomo, exprimindo sua própria mundividência, pouco importa coincida ela ou não com a ideologia própria do autor da obra; a polifonia ocorre quando cada personagem fala com a sua própria voz, expressando seu pensamento particular, de tal modo que, existindo $\mathrm{n}$ personagens, existirão n posturas ideológicas. (LOPES, 2011, p. 74).

Não importa, então, a quantidade e variedade de personagens, mas a capacidade de exprimirem pontos de vistas distintos. A questão se torna complexa quando analisamos as declamações, porque embora as personagens subalternas apareçam com frequência e sejam as protagonistas dos casos judiciais, inclusive sendo seus próprios advogados, como o jovem da poção de ódio, os argumentos apresentados ao mesmo tempo contribuem para a manutenção da ordem social e também rompem com ela.

Para que a defesa de uma prostituta tenha credibilidade, a primeira recomendação é que o declamador assuma a persona de um advogado. Imbuído deste êthos de orador, mais próximo do ideal do uir bonus, o aluno é capaz de construir uma argumentação que é empática com a 
situação da meretriz, numa atitude complacente frente a ela, quando diz que a poção foi o último recurso empregado por uma jovem honesta, que só se tornou prostituta por fatores econômicos, impossibilitada de pagar o dote para um matrimônio. Mas ainda que seja necessário elaborar o êthos da meretrix bona ao longo de toda a narrativa, enfatizando que apesar da sua ocupação, a moça pode ser considerada inocente e íntegra, é defendido - como um argumento geral - que uma mulher e sobretudo uma prostituta tem o direito, ainda que nesta situação específica, de rejeitar e de também escolher os seus clientes.

Ao aplicarmos a teoria bakhtiniana aos Estudos Clássicos, é preciso ponderarmos sobre o contexto social de produção do discurso, que difere histórica e cronologicamente do contexto contemporâneo. $\mathrm{O}$ que pode ser visto como uma defesa restrita dos direitos da mulher, numa sociedade atual em que tanto é pregada a liberdade dos corpos, para os antigos representava uma visão revolucionária sobre a condição da mulher na ordem social, que só era possível dentro do âmbito das declamações, em que a inspiração para a personagem vinha do gênero cômico, ao qual está vinculado o conceito da carnavalização, "quando a ordem, o bom senso, as leis e as hierarquias que organizam nosso mundo cotidiano são virados para o avesso, e as distâncias firmemente estabelecidas e preservadas pelas convenções são abolidas" (LOPES, 2011, p. 77). Em outras palavras, a contestação da ordem só é permitida porque é fictícia e temporária, não atingindo nenhum efeito concreto na hierarquia real.

Toda a base da Comédia Nova também está vinculada a este conceito, em que escravos são mais inteligentes que seus mestres e os enganam ou adolescentes enfrentam a autoridade do pater famílias. $\mathrm{Na}$ conclusão das peças, muitos dos personagens que tentam subverter a ordem são punidos ou têm seus planos frustrados. Segundo Gruber (2008, p. 9), os pontos de interseção entre a declamação e a comédia são principalmente o tratamento de temas domésticos ou cotidianos e a promoção de um retorno aos valores. As comédias terminam com reencontros, casamentos e resolução dos conflitos apresentados na peça, enquanto o objetivo do declamador seria o de solucionar, através da argumentação, conflitos similares. 
Ainda considerando a teoria de Bakhtin, a declamação ou qualquer outro texto literário não devem ser lidos como a expressão fiel da realidade histórica, porque possuem elementos de ficção e de não compromisso com esta mesma realidade. No entanto, é natural que aspectos concretos da sociedade se manifestem de alguma forma no discurso, uma vez que ele é produzido dentro de um contexto histórico específico, do qual o autor faz parte, como observador, como participante e no caso do gênero declamatório, como cidadão. Apesar disso, mesmo que as personagens da prostituta e do jovem pobre apareçam com contornos que emulam em certo nível o mundo material, é preciso "antes tentar compreender como ocorre, nos textos da literatura, a produção do sentido: como o discurso literário vem a significar o que significa?" (LOPES, 2011, p. 69).

As declamações como um exercício escolar têm uma função definida, que não era a de defender as minorias, mas a de treinar as habilidades retóricas dos jovens letrados para que pudessem apropriar as vozes inferiores ao seu discurso. Bloomer (1997, p. 212) afirma que este era um dos principais desafios, já que os adolescentes de classe mais alta estavam em certa medida isolados do convívio com as classes menos abastadas.

A fantasia das declamações reflete a da comédia romana: homens livres e escravos são tão promovidos que são ou têm advogados. O filho fala contra o pai. Pode-se dizer que talvez uma contenda geracional e social esteja emergindo, mas mais concretamente, os alunos romanos estavam performando um tipo de encenação praticada na construção das categorias. ${ }^{8}$ (BLOOMER, 1997, p. 212, tradução nossa).

A afirmação de Bloomer (1997) vai ao encontro do conceito de carnavalização de Bakhtin (1981, p. 105), corroborando a ideia de que os

\footnotetext{
8 "The fantasy of declamations mirrors that of Roman comedy: freedman and slaves are so promoted that they are or have advocates. The son speaks against the father. Generational and social strife may be said to be surfacing, but more concretely, Roman schoolboys were performing a sort of role-playing practiced in category-making."
} 
declamadores assumem máscaras de diferentes sujeitos sociais e encenam situações durante as sessões de declamação, bem como os atores faziam na comédia e no teatro, que não necessariamente poderiam acontecer na realidade concreta. Nesse mundo fantasioso, prostitutas podem ser aclamadas por terem encontrado a cura para o amor, relativizando o fato de ter envenenado um cliente. ${ }^{9}$

Ao mesmo tempo em que as declamações efetivavam o seu papel na propagação dos valores da elite, ao mostrar qual era o comportamento social e de gênero esperado dos futuros cidadãos elegíveis para cargos públicos, o trabalho com as personagens também era da ordem cultural, porque exigia o conhecimento do cânone.

Mais fundamentalmente, já através da escola de retórica, o garoto iria soar como um jovem romano, sabendo não apenas epigrama, divisio e praeteritio, mas também o estoque cultural de exempla históricos e a experiência compartilhada de envolvimento anacrônico, imaginativo com o "passado", com a "história". ${ }^{10}$ (BLOOMER, 1997, p. 213, tradução nossa).

E o que seria esta experiência compartilhada, senão o próprio cânone, que é formado pelo valor atribuído às obras, de acordo com os aspectos culturais vigentes em cada época e em cada sociedade? Dentro de uma elite intelectual, não é exigido apenas o conhecimento do cânone,

\footnotetext{
9 "Admiti aquilo que mais deveríeis reverenciar, admirar: uma mulher inventou um remédio para o amor. [...] É um crime que o maior dos remédios perca a sua glória por causa da alcunha do seu criador. Admiraríamos o homem que desse aquele remédio contra uma meretriz" (Decl. maiores, 15.8, tradução nossa).

"Accipite, quod magis debeatis stupere, mirari: remedium amoris mulier invenit. [...] facinus est, quod maximum remedium gratiam sui vocabulo perdit auctoris. miraremur hominem, qui illud contra meretricem dedisset."

10 "Most fundamentally, once through rhetoric school, a boy would sound like a young Roman, knowing not only epigram, division and praeteritio, but the cultural stock of historical exempla and the shared experience of anachronist, imaginative involvement with the "past", with 'history'."
} 
mas também práticas políticas e sociais que estejam de acordo com as ideias propagadas pelas grandes obras.

\section{Conclusão}

Isto significa, então, que não havia contestação real ou possibilidade de polifonia dentro das declamações? Podemos reduzir a defesa da prostituta apenas a um exercício que busca o desenvolvimento de habilidades retóricas através da apropriação das vozes das minorias? Concordamos com Bloomer (1997, p. 215), ao afirmar que a literatura é uma instituição social que negocia identidades e alianças. As declamações permitiam representações mutáveis de como a mulher, o filho e o escravo deveriam agir e falar. Como as declamações eram também uma forma de entretenimento, sendo encenadas para uma audiência e não contavam com a palavra final de juízes em um tribunal, cabia ao próprio público julgar.

Bloomer (1997, p. 215) sugere que, desta forma, algumas ficções e exempla poderiam ser redefinidos por esta mesma elite ao longo do tempo, tornando alguns papéis mais flexíveis na literatura, reorganizando as noções de status e de autoridade, que possam ter tido talvez consequências materiais. O gênero declamatório e as controvérsias podem ser entendidos como um espaço no qual a realidade material se manifesta, assim como acontece com qualquer outro texto literário, sujeito a trazer as marcas da realidade social que o autor observa. No caso das declamações, também levantamos a hipótese de que tais discursos influenciaram mudanças sociais concretas.

A disseminação dos exempla e o constante reenfrentamento de situações morais e sociais polêmicas poderiam causar pequenas fissuras no tecido social. A partir daí, percebemos a possibilidade de flexibilização de determinadas leis, surgimento de novas alianças entre a elite e mudanças na relação entre indivíduos marginalizados e a aristocracia, num constante movimento dialógico, que ora contribuía para a afirmação dos valores culturais e ora os contestava. Tal processo, é claro, revela muito mais sobre as elites e suas estratégias de lidarem com os subalternos do que sobre os marginalizados por si mesmos, constatando que essas relações não eram estáveis e que a autoridade não 
era sempre inquestionável. A ideologia dominante permanecia sendo a da aristocracia, mas ela é constantemente renegociada, redefinida e reafirmada, através do instrumento do discurso e da retórica.

\section{Referências}

ANDERSON, William S. Anger in Juvenal and Seneca. Publications in Classical Philology, Berkeley, v. 19, n. 3, p. 127-196, 1964.

BAKHTIN, M. M. Problemas da Poética de Dostoiévski. Tradução de Paulo Bezerra. 1. ed. Rio de Janeiro: Forense Universitária, 1981.

BARTHES, Roland. A morte do autor. In: . O rumor da língua. Tradução de Mário Laranjeira. São Paulo: Brasiliense, 1988 [1968]. p. $65-70$.

BLOOMER, Martin. A preface to the history of declamation: whose speech? Whose history? In: HABINEK, Thomas; SCHIESARO, Alessandro. The Roman Cultural Revolution. Cambridge: Cambridge University Press, 1997.

BONNER, S.F. Roman Declamation in the Late Republic and Early Empire. Liverpool: Liverpool University Press, 1949.

BOOTH, Wayne C. The Rhetoric of Fiction. 2. ed. Chicago: University of Chicago Press, 1983 [1961].

CLAY, Diskin. The Theory of Literary Persona in Antiquity. Materiali e Discussioni per l'Analisi dei Testi Classici, Pisa, n. 40, p. 9-40, 1998. DOI: https://doi.org/10.2307/40236116.

COMPAGNON, Antoine. O demônio da teoria. Literatura e senso comum. Tradução de Cleonice Barreto Mourão e Consuelo Fortes Santiago. Belo Horizonte: Editora UFMG, 2014.

CONNOLLY, Joy. Imaginative fiction beyond social and moral norms. In: DINTER, M.; GUÉRIN, C.; MARTINHO, M. (org.). Reading Roman Declamation: the Declamations Ascribed to Quintilian. Berlim: De Gruyter, 2015. p. 191-207. DOI: https://doi.org/10.1515/9783110352511010 . 
CORBEILL, Anthony. A Student Speaks for Social Equality in the Roman Classroom. In: DINTER, M.; GUÉRIN, C.; MARTINHO, M. (org.). Reading Roman Declamation: the Declamations Ascribed to Quintilian. Berlim: De Gruyter, 2015. p. 11-24. DOI: https://doi. org/10.1515/9783110352511-003.

EDWARDS, Catherine. Unspeakable Professions: Public Performance and Prostitution in Ancient Rome. In: HALLET, Judith; SKINNER, Marilyn. Roman Sexualities. Princeton: Princeton University Press, 1997. p. 66-95.

FALCÓN, Rafael Sento-Sé Guimarães. A educação do orador: tradução e estudo do livro II da Institutio Oratoria. 2015. 124 f. Dissertação (Mestrado em Letras Clássicas) - Faculdade de Filosofia, Letras e Ciências Humanas, Universidade de São Paulo, São Paulo, 2015.

FIORIN, José Luiz. Interdiscursividade e intertextualidade. In: BRAIT, Beth (org.) Bakhtin. Outros conceitos-chave. São Paulo: Contexto, 2005. p. 161-193.

FOUCAULT, Michel. O que é um autor? Tradução de António Fernando Caiscais e Eduardo Cordeiro. 3. ed. Lisboa: Vega, 1997 [1969].

GILULA, Dwora. The Concept of the 'bona meretrix'. A Study of Terence's Courtesans. Rivista di Filologia e di Istruzione Classica, Torino, v. 108, p. 142-165, jan. 1980.

GONZÁLEZ, Ana M. Rodríguez. Las declamaciones quintilianeas y la experiencia jurídica romana. In: Seminarios Complutenses de Derecho Romano: Revista Internacional de Derecho Romano y Tradicion Romanística, Madrid, n. 28, p. 941-957, 2015.

GREENE, T. M. The Light in Troy: Imitation and Discovery in Renaissance Poetry. New Haven: Yale University Press, 1982.

GRUBER, Heather Irene Waddell. The Women of Greek Declamation and the Reception of Comics Stereotypes. 2008. 173 f. Tese (Doutorado em Filosofia) - University of Iowa, Iowa, 2008.

LANGLANDS, Rebecca. Sexual Morality in Ancient Rome. New York: Cambridge University Press, 2006. DOI: https://doi.org/10.1017/ CBO9780511482823. 
LOPES, Edward. Discurso literário e dialogismo em Bakhtin. In: BARROS, Diana Luz Pessoa; FIORIN, José Luiz. Dialogismo, polifonia, intertextualidade: em torno de Bakhtin. 2. ed. São Paulo: EDUSP, 2011. p. 63-81.

MIOTTI, Charlene Martins. Ridentem dicere verum: o humor retórico de Quintiliano e seu diálogo com Cícero, Catulo e Horácio. 2010. 224 f. Tese (Doutorado em Linguística) - Instituto de Estudos da Linguagem, Universidade Estadual de Campinas, Campinas, 2010.

PEREIRA, Marcos A. Natureza e lugar dos discursos gramatical e retórico em Cícero e Quintiliano. Phaos, Campinas, v. 1, p. 143-157, 2001.

PERNOT, Laurent. Rhetoric in Antiquity. Translation by W. E. Higgins. Washington: The Catholic University of America, 2005.

REZENDE, Antonio Martinez de. Rompendo o silêncio: a construção do discurso oratório em Quintiliano. 2009. 280 f. Tese (Doutorado em Estudos Linguísticos) - Faculdade de Letras, Universidade Federal de Minas Gerais, Belo Horizonte, 2009.

SCHOECK, Richard J. Intertextualidade e cânone retórico. Rónai: Revista de Estudos Clássicos e Tradutórios, Juiz de Fora, v. 5, n. 1, p. 3-15, 2017. DOI: https://doi.org/10.34019/2318-3446.2017.v5.23208.

SCHWARTZ, Pablo. Estratégias da tradição: Cícero nas Declamationes de Sêneca, o Retor, e no Dialogus de oratoribus de Tácito. 2004. 240 f. Tese (Doutorado em Letras Clássicas) - Faculdade de Filosofia, Letras e Ciências Humanas, Universidade de São Paulo, São Paulo, 2004.

STRONG, Anise K. Prostitutes and matrons in the Roman World. New York: Cambridge University Press, 2016. DOI: https://doi.org/10.1017/ CBO9781316563083.

SUSSMAN, Lewis A. The Major Declamations Ascribed to Quintilian: a Translation. Frankfurt am Main: Peter Lang GmbH, 1987.

VEESER, Harold Aram (ed.). The new historicism. New York: Routledge, 1989.

Recebido em: 31 de maio de 2020. Aprovado em: 02 de julho de 2020. 